\title{
Undergraduate Perceptions of Information Literacy: Defining, Attaining, and Self-Assessing Skills
}

\author{
Melissa Gross and Don Latham
}

This investigation uses interview data on student conceptions of and experiences with interacting with information. In addition, student scores on the Information Literacy Test (ILT) provide data that allow for comparison of student perceptions to their level of information literacy as measured by a standardized test. A relational approach, informed by competency theory and the imposed query model, provide the framework for the study design and interpretation of the data. Findings reveal a general view of information literacy focused on product rather than process, a perception of achieving information skills on their own, a preference for people over other information sources, and an emphasis on personal interest as key to successful information seeking.

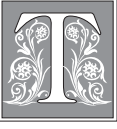

he premise that students must be information literate to be successful in their work and personal lives is one that is embraced by many. Nonetheless, research shows that not all students come to higher education with the skills necessary to be called information literate. A recent study performed by Educational Testing Service (ETS) found that only 13 percent of 3,000 college students and 800 high school students who took the ETS Information and Communication Technology test scored as information literate. ${ }^{1}$ In addition, other research indicates that many students leave higher education without ever attaining these much-needed information literacy skills. ${ }^{2}$
There has been a great deal written in the literature of library and information science about how to help students attain information literacy, and a wide variety of creative interventions have been developed and tested that utilize educational theory, developmental theory, and various media to respond to the learning needs of students. Although many successes are reported, there is also evidence in the literature that students who receive information literacy instruction do not necessarily learn, or retain, what is taught. While this in itself may not be surprising, what is surprising is that students who are unable to demonstrate information literacy competency nevertheless exhibit a high level of confidence in their ability

Melissa Gross is Associate Professor and Don Latham is Associate Professor in the College of Information at Florida State University; e-mail: mgross@fsu.edu and latham@fsu.edu. The authors wish to thank the Online Computer Library Center and the Association of Library and Information Science Educators for their kind support of this work in the form of an OCLC/ALISE LISRGP grant. We would also like to thank Annette Goldsmith for her assistance in transcribing the interviews. 
to find and use information effectively. ${ }^{3}$ Examination of the relationship between low skill levels and high confidence levels and the consequences of this problematic combination provides a new approach to the well-established problem of how to ensure that students achieve information literacy prior to entering the workforce.

\section{Literature Review}

Competency theory offers one potential explanation for why students who are not information literate report a high level of confidence in their ability to seek, evaluate, and use information. According to research performed in the domain of psychology, people who are incompetent, particularly in areas in which people commonly have some orientation, tend to believe that their skills are above average and to overestimate their performance on a skills test. ${ }^{4}$ This outcome has been demonstrated in skill areas such as poor readers' ability to assess their own reading comprehension, low-performing students' estimates of performance on tests, and self-evaluations by medical students concerning their interviewing skills. ${ }^{5}$

Other interesting characteristics of people who lack competency in a particular domain are that they are nonetheless very confident about their abilities, do not learn from failure, and are unable to recognize expertise in others. Kruger and Dunning theorize that people who lack skills in a domain also lack the metacognitive skills that would allow them to better assess their own abilities and make more realistic estimates of their performance. The good news is that it is possible to overcome incompetence. When people gain skills in a domain, they are better able to assess their own skill level, recognize the abilities of others, and make better estimations of their own performance.

In 2005, Gross outlined the implications of competency theory for students who have nonproficient information literacy skills and for information literacy instruction, if it can be demonstrated that competency theory applies to this do- main. ${ }^{6}$ One of the chief points she makes is that people who have a lot of confidence about their level of ability are unlikely to seek opportunities to build skills they think they already have. Likewise, students who are unable to recognize expertise in others will also be unlikely to take advantage of the help librarians can offer them.

To determine if competency theory applies to students who have nonproficient information literacy skills, Gross and Latham replicated the Kruger and Dunning studies, focusing on the information literacy skills of incoming college freshmen. ${ }^{7}$ In this study, participants were asked to predict their performance on an information literacy skills test and to predict how their performance would compare to the scores of other participants in the study both before and after taking an information literacy skills test.

The findings from this study demonstrate an association between low-level skills and an inflated self-view of ability for estimates of performance made both before and after taking an information literacy skills test. Further, as in the Kruger and Dunning studies, students with scores in the nonproficient range also estimated that their performance was above average as compared to their peers. Another interesting finding among this group of participants is that students with high GPA and SAT/ACT scores (top $10 \%$ of incoming class) are not necessarily information literate.

One of the fundamental tenets of evaluation is that achievement be measured against a defined benchmark, set of standards, or established goals for performance. Information literacy is a term that has been defined by information professionals, although the extent to which it has been adopted by others outside the profession is unknown. The definition of information literacy that guides academic librarianship is provided by the Association of College and Research Libraries (ACRL). ACRL defines information literacy as "a set of 
abilities requiring individuals to recognize when information is needed and have the ability to locate, evaluate, and use effectively the needed information." This definition is further specified by a set of competency standards that emphasize five key skills. A person who is information literate: ${ }^{8}$

1. Determines the nature and extent of the information needed.

2. Accesses needed information effectively and efficiently.

3. Evaluates information and its sources critically and incorporates selected information into his or her knowledge base and value system.

4. Individually or as a member of a group, uses information effectively to accomplish a specific purpose.

5. Understands many of the economic, legal, and social issues surrounding the use of information and accesses and uses information ethically and legally.

This definition was also accepted and used by the researchers in the Gross and Latham study discussed above. However, it seems unlikely that the students who participated in the study had the ACRL definition in mind when they estimated their performance on the Information Literacy Test (ILT). Could it be that it is a difference in definition, or experience with information, that is behind these inflated self-views? While not being aware of and/or not accepting of the formal definition of a concept may in itself be evidence of incompetence, studies have shown that perceptions of information literacy have varied over time and are open to reinterpretation. ${ }^{9}$ Further, as concerns undergraduate student populations, information literacy training is not consistently provided to students in grades $\mathrm{K}-12$ in the United States, and little research has been done on the perceptions held by students in higher education concerning what information literacy is. The main purpose of the investigation reported here is to begin to explore undergraduates' conceptions of and experience with in- formation to develop an understanding of how these students perceive information literacy.

Christine Bruce had similar concerns when she studied how educators in higher education perceive the concept of information literacy. In her book, The Seven Faces of Information Literacy, she details her research methodology, which takes a relational approach to understanding the subject's engagement with information. ${ }^{10}$ Her approach is applied here to begin to develop an understanding of how undergraduates see and experience information. This framework has been extended in the current study to include perceptions of information literacy differentiated according to the dichotomous view of information seeking provided by the imposed query model. The imposed query model distinguishes between information seeking that is set in motion by someone else (such as a teacher giving an assignment) and information seeking that is self-generated. As the goal of information literacy is not only to help students excel at school but also to become lifelong learners, understanding perceptions of information literacy as it pertains to both the academic and personal dimensions of experience should provide a rich picture of the place of information literacy in the lives of students. Competency theory also plays a part in the study design and in the analysis of the data, as the dual characteristics of incompetence and confidence may also color experiences with information.

\section{Research Questions}

The following research questions are explored in this study:

\section{Perceptions of Information Literacy}

1. What are freshmen's understandings of what IL is?

2. Do freshmen's conceptions of IL vary for self-generated and imposed information seeking?

3. What knowledge base do freshmen see as necessary to become information literate? 
4. What skills do freshmen see as necessary to be competent information seekers?

5. How do freshmen define successful information seeking?

II. Perceptions of Attaining Information Literacy

1. How have freshmen learned what they know about IL?

2. Are freshmen's ideas about learning IL different for self-generated and imposed information seeking?

3. How do freshmen think that the knowledge base necessary for IL is best achieved?

4. How do freshmen think that the skills necessary for IL are best achieved?

III. Self-views of Information Literacy

1. How do freshmen describe themselves in terms of their IL competency?

2. Do freshmen's views of their own information seeking vary for self-generated and imposed information needs?

3. How do freshmen assess their own knowledge base as regards IL?

4. How do freshmen assess their own skill levels as regards IL?

5. How do freshmen's self-assessments of IL compare to their scores on a standardized test of information literacy?

\section{Methodology}

Data was collected in a two-step process. First, subjects participated in a semistructured interview with the researchers. Then, within one week of the interview, participants completed the Information Literacy Test (ILT) in a proctored environment at the university testing center. The interviews provided data on student conceptions of and experiences with interacting with information. The ILT provided an objective assessment of participants' skills to allow for an understanding of student perceptions as they might relate to their level of information literacy (IL).

Students were solicited for participation in this study via e-mail. In an effort to include the views of students with both proficient and nonproficient information literacy skills, the top 10 percent and bottom 10 percent of the freshmen class were targeted, based on admissions data: high school GPA and standardized test score (ACT or adjusted SAT). As an incentive to participate, students were offered gift cards to the university bookstore. Participants received a $\$ 30$ gift card for the interview and a $\$ 20$ gift card for taking the ILT.

While the goal for including 20 subjects in the research was met, bottom-tier students proved difficult to recruit. However, previous research (as well as the findings here) indicates that there is not necessarily a correlation between achievement, as measured by GPA and SAT/ACT scores, and information literacy skills. ${ }^{11}$ Also, the gap in previous academic performance between low-tier and high-tier university students is relatively narrow. All students performed well enough to earn entry to the university and were completing their first year.

\section{Interviews}

Interviews took place in a faculty office at the university and were attended by the participant and both of the researchers. One researcher (female) conducted the interview and the other (male) took notes. All interviews were digitally recorded and lasted between 45 minutes and one hour. During the interview, the interview schedule (see Appendix A) was used as a starting point to ask students

- To describe a recent imposed information-seeking task.

- To describe a recent self-generated information-seeking task.

- To describe their perceptions of IL.

- To describe how IL skills are best attained.

- To describe their views of their own IL skills.

The interview schedule was pretested with undergraduates and refined before use in the study. However, as the interviews were semistructured in nature, these questions served only as a guide. The course of the actual conversations followed the lead and related interests of each interviewee. 
The recorded interviews were transcribed by a graduate assistant, and analysis followed the constant comparative method..$^{12}$ The researchers began discussion of the interview content as data was collected. This analysis allowed for the identification of common events, activities, and perceptions across interviews, as well as awareness of the development of themes and categories as the interviews progressed. In this way, the completion of one interview informed preparation for the next. This process continued as the transcriptions were completed and then analyzed independently by each researcher. The researchers then discussed each transcript and analyzed the whole study using Hyper-research software.

Throughout this process, the potential for researcher bias was an active area of self-awareness for the researchers. The main concern was the possibility that students might be inclined to say what they felt the interviewers (who were identified as faculty) wanted them to say. It was important that the students were made to feel free to share their ideas and experience. To facilitate a free flow of ideas, the researchers worked to provide an atmosphere that was casual and friendly. The researchers also sought to make it as clear as possible that the research was interested in understanding student views and that the researchers had no stake in any particular outcome, except the desire to improve instruction.

\section{Testing}

Within one week of being interviewed, participants took the ILT in a proctored environment at the university testing center. The ILT, developed at James Madison University (JMU), is a computer-based, objective, and validated test of information literacy. ${ }^{13}$ It measures all of the ACRL Competency Standards except for one: the effective use of information to accomplish a specific purpose (Standard 4). This test was chosen as it has been consistently used by JMU for a number of years, has been widely adopted by other universities, and allows for comparison to other data collected by the researchers in other, related studies.

Because participants were unlikely to have any personal stake in their performance on the ILT, several steps were taken to encourage them to perform well. First, they were encouraged to do their best on the ILT before they left the interview; second, all participants received a $\$ 20$ gift card when they completed the test; and, third, they were advised beforehand that those study participants who scored in the top 15 percent on the ILT would be entered in a lottery to receive one of two $\$ 50$ gift cards.

To further ensure that student scores were valid, a response-time analysis was performed by researchers at JMU. This analysis compares the individual's response times on each question to established benchmarks of the amount of time a student paying attention to the question will spend answering it. The responsetime analysis performed on this data set indicates that these study participants gave each question a reasonable amount of attention in completing the ILT.

\section{Findings}

The participants in this study can be described as follows. The majority (15, or $75 \%$ ) are female: the remainder (5, or $25 \%$ ) are male. All participants were traditional undergraduates in the sense that they matriculated directly from high school to the university and all were 18 or 19 years of age at the time the study took place.

Most of the participants (17, or $85 \%$ ) represent the top 10 percent of their class. Only three participants $(15 \%)$ were from the bottom 10 percent of their class. These subjects represent a variety of majors, and two students were pursuing double majors. Participants included eight students studying science, technology, engineering, or math; five majoring in business/economics; three music majors; three humanities majors; two education majors; and one student who had not yet declared a major.

Only one student scored in the nonproficient range on the ILT (38 or lower), with a score of 38 . Most of these students (18, or 
$90 \%)$ scored in the proficient range with scores between 39 and 53. Only one student earned a score in the advanced range (a score of 54 or greater). As a group, these students represent individuals who have demonstrated "proficient" information literacy skills.

The overarching goal of this study is to explore undergraduates' conceptions of and experience with information to understand their perception of what it means to be information literate. To investigate this question, three sets of research questions were articulated that focus on these respondents' perceptions of information literacy as a concept, their perceptions of how information literacy is attained, and their descriptions of their own information literacy skills. Findings for each research question set are discussed in the following sections, including findings for information literacy as an umbrella term and student views regarding information literacy in imposed and self-generated information-seeking situations.

\section{Perceptions of Information Literacy}

Student perceptions and experiences with information are used in this study to develop an idea of how students conceptualize information literacy. As it turned out, none of the participants in this study were familiar with the term, and all found it difficult to decode when they were presented with it. A common approach students used to try to unpack the term was to start with the concept of "literacy" and to try to apply familiar types of literacy (reading and computer literacy) to the word "information." This logical approach was not a successful one for them and ultimately did not allow them to derive a definition from the phrase itself.

This difficulty made itself clear during the pretest of the interview instrument. To avoid defining the term "information literacy" for participants and possibly skewing responses, the researchers employed alternative phrasing such as "seeking, finding, and using information" and asked participants to describe step-by-step how they did these things in school assignments and in their personal lives outside work and school. The question of what information literacy might be was moved to the end of the interview, as a wrap-up to the conversation.

What are freshmen's understandings of IL? When asked to recall a recent assignment in which they needed to go further than the class text or other teacher-provided materials, however, many interviewees stumbled at first. Participants who mainly had classes in science, technology, and math reported that research skills were not relevant to their area of interest. Others made statements such as, "I haven't done a lot in my last couple literature classes, they were literature classes and didn't really entail outside work." However, all students who were unable to talk about research assignments undertaken during their freshman year were able to provide examples from their high school experiences to discuss.

In describing their information-seeking experiences and in conceptualizing what aspects of their information behavior help them to be successful, participants focused mainly on their ability as thinkers and the skills they hold as learners. Library, Internet, and computer skills were not introduced into the discussion by these students. The idea that successful information seeking need only be measured by the ability to find the information, not the process used to get there, was repeated time and time again. When queried about the skill sets needed to be a competent information seeker, students emphasized traits such as curiosity and perseverance, the ability to synthesize information, and understanding the relationship between sources and questions. Knowledge and skill sets such as an understanding of Boolean logic or familiarity with databases were not singled out by participants for discussion.

When asked if they had informationseeking skills they would like to improve or acquire, participants again stumbled. Some expressed a desire to know more about how to use the university library, 
but most were unable to articulate an answer to this question. There was little sense among this group that there are more skills or a wider knowledge base to be had regarding their information behaviors. One respondent asked outright, "What is there to know?" and continued later, "I honestly don't know how much greater information literacy needs to be, even on a higher research level... I think once you learn the basic level there isn't a ton of room for improvement."

Self-generated versus Imposed Information Seeking. Student descriptions of their information-seeking process and their ideas about how looking for information for a school assignment and looking for information for their own use revealed many conceptual similarities in approach, but the two types of information seeking were described quite differently in terms of how participants experienced them. These differences are summarized in table 1.

Imposed information seeking in the form of school assignments is seen as a highly formalized, constrained process. The reason for this is two-fold. One set of constraints is the highly structured nature of assignments where topic, source, type and number, due date, and presentation of findings are determined by the assignment, not by the information seeker. The other is the need to respond in a way that will maximize the grade, or at least allow the student to pass, rather than focusing on what is being learned. Maximizing performance, enjoyment of the research process, and learning are all tied to the level of interest, background knowledge held, and motivation that the student brings to the process. While some students could find sufficient motivation in their desire to get a good grade, for many an inability to develop interest in a topic made imposed information seeking almost impossible.

One respondent said, "Yeah. There's a point where with papers like that, where you just have to do it, sometimes. And sometimes you do get a hard topic, or you pick something and you think later, what was I thinking? But you just have to do it. And when it gets to that level, it's really not fun anymore." Another respondent shared, "If I'm looking for information, I want to know about it, I'm curious. Cause if I'm not curious about it, I don't care. I'm not going to go out looking for information I either don't need or don't want or don't, no, I don't care. I mean, I was curious about, because we got to pick our topics for the paper, I was curious about the topic. I went out of my way to go to the library on an off day and to search through like seven aisles of books to find what I was looking for."

Other representative comments include: "if you're interested, you're definitely more likely to try harder, and produce a better result that somebody who is disinterested, or, you know, thinks negatively of the topic, or whatever"; "If you should happen to not like the topic, well, that was a bit of a challenge for me. I was actually lucky that I was actually interested in that material because otherwise it would have been a real pain to do that, that kind of paper"; and "It just depends on whether they have a passion

\begin{tabular}{|l|l|}
\hline \multicolumn{2}{|c|}{ TABLE 1 } \\
\hline \multicolumn{2}{|c|}{ Imposed Versus Self-generated Information Seeking } \\
\hline \hline Imposed = Constrained & Self-Generated = Open \\
\hline $\begin{array}{l}\text { A limited number of acceptable resources } \\
\text { can be used (“academic" sources needed) }\end{array}$ & $\begin{array}{l}\text { A wealth of resources are available (though } \\
\text { fewer tend to be consulted) }\end{array}$ \\
\hline Deadline/due date & You decide when you are done \\
\hline $\begin{array}{l}\text { Need to develop interest (especially if it } \\
\text { isn't naturally there) }\end{array}$ & $\begin{array}{l}\text { Motivated by genuine interest, even if that } \\
\text { interest is casual }\end{array}$ \\
\hline Product/presentation required & Product not required \\
\hline
\end{tabular}


for what it is they're trying to learn about. Or when it comes to a research project, how good of a grade they want to get. "

Having background knowledge of a topic was also seen as an aid to doing well on assignments. Respondents report feeling more confident when researching in an area they already know something about, even if it is not a topic that they hold a great passion for.

Self-generated information seeking, in contrast, is experienced in a very fluid and open way. It is the essence of selfgenerated information seeking that it is inherently interesting to the information seeker, prompted either by personal circumstance or personal curiosity. The ability to use any resource type to resolve their information needs appeals to these respondents. They talked about a wide range of resource types in their information use: people; the Internet, including social networking sites, such as Facebook; books; newspapers; TV; videos; magazines; pamphlets; the telephone, and personal experience. However, in specific information-seeking situations, they actually use fewer sources than they do with imposed queries.

Another freedom associated with selfgenerated information seeking is the ability of the individual to set his or her own timetable or even give up the search if it begins to lose relevance. The lack of a due date for most personal questions also allows interest to be an ongoing experience as well as a momentary one. Likewise, while personal information seeking may result in some kind of product such as artwork or a Facebook or MySpace page, it is less product oriented than imposed information seeking. Outcomes such as being able to apply information to a problem, make a decision, feel informed, or salve curiosity are the most common goals of self-generated information seeking.

Preferred Resources. By far, for both imposed and self-generated information seeking, the most popular resources are other people and the Internet. This general attitude is summed up in comments such as, "Very often. I would say I use, I would say as often as other people use the Internet, I use people and the Internet. I usually use people and the Internet just about the same" and "it makes it more believable to hear it from a person rather than from, well, I know the information on the Web came from a person, but it's comforting to know that there's someone who actually said that."

All but three of the students interviewed said that other people come to them with their information needs. All but one of the participants said they seek information from others in their information seeking. In addition, some respondents report that they go out of their way to be the person others would go to for information or described people they knew who were assertive about taking on this role. For example, one participant learned to use the music library from a student who is a year ahead of him in the program. He didn't ask for her help: "She made herself the person to ask," and he in turn feels this might be a role he will take on in the future.

Participants described people as providing three distinct types of information help, which can be categorized in three distinct roles. In their information seeking, these students sought people who could serve as informants, agents, or trainers. For each role, the two major considerations in approaching someone else for information help are the person's knowledge base and his or her availability. Students prefer to seek help from people they already have an established relationship with, but they may also solicit help from strangers who appear available to talk and approachable. However, it is not uncommon for students to ask for help from someone sitting next to them in the classroom, library, or lab, or from someone in their dorm.

Sometimes people are treated as information sources themselves, much like checking a reference book or looking up a fact on the Internet. In this role, the informant is expected to have the infor- 
mation needed (what is the name of the greatest song in the world?) or are sought for the value of some personal experience they have (how do you like that car you bought?).

On the other hand, people are also sought for their ability to find information. In this case, the person sought is asked to take on the role of "agent," which means that they will act as a surrogate in finding the needed information and will return with the needed data, answer, or resolution. Interestingly, students who report acting as agents are less likely to use others as informants and routinely perform as agents for a variety of people including classmates, family, and friends.

The third reason these participants sought help from others was to learn a skill they need, rather than to gain knowledge. In this case, they are looking for someone who can serve as a "trainer." Typically, skills are sought on an as-needed basis and tend to represent quick questions that are specific and well defined (how do I make a pdf out of my word doc?). As mentioned above, availability is often the first consideration here; personal relations are preferred over an authority figure such as a professor or a librarian.

The other preferred resource, the Internet, is often the first stop for both imposed and self-generated information seeking. The common approach is to use a search engine, most often Google, as the starting point for any information search. The only time this approach is amended is if the professor imposes the need to use a specific proprietary database, and then the search begins there. Several students described their facility with online searching including the use of Boolean logic and limiting searches, among other methods. However, students did not seem to realize that the proprietary databases they used were provided by the library or to differentiate well between the library catalog and other databases the library provides online.

Participants did discuss the need to think about who is providing information on the Internet and the importance of using multiple resources to check information, but they also saw this need as varying with the importance of the question they are pursuing. For much information seeking, particularly casual information seeking, source quality wasn't seen as particularly important. On the imposed side, the requirement to use "academic sources" appears to preempt any danger; and, on both the imposed and the self-generated sides, the concerns about source quality are minimal. As one student expressed it, "you hear teachers and professors tell you all the time, be wary of the Internet. But I've never really had a bad experience where I've had some, like, horribly wrong information or whatnot."

\section{Perceptions of Attaining Information Literacy}

When asked how they learned what they know about information seeking, all but three of the respondents consider themselves primarily to be "self-taught." They describe "growing up with the Internet," adapting to electronic information naturally, and using trial and error to learn what they want to know. Half of the respondents also credited family members as playing an important part in their attainment of information-seeking skills. In six of these cases, participants specifically mentioned the important role their mother played in getting them started.

Formal information literacy training, in the library or in the classroom, was not a common experience for these participants. For those who received formal training, it tended to take place in the elementary school library. A couple of participants recalled a specific teacher in their first year at the university who made a point of teaching information literacy in the classroom. For the most part, however, credit to teachers mainly involved the fact that assignments in high school required students to learn on their own and ensured that they were practicing information seeking. No difference was reported between the attainment of 
information-seeking skills for imposed or self-generated situations.

While it was difficult for respondents to name skills they wanted to gain or improve, they had very clear ideas on how they would prefer to do this. These participants want to learn new skills at the point in time when the skills are needed, in person in a one-on-one learning situation, from someone they feel comfortable with - and the session should include the chance to practice.

Students were also amenable to the idea of learning information skills in a classroom environment; it just wasn't their first choice. However, classroom instruction should still incorporate many aspects of the criteria described above into the learning experience. These participants stress the need to be taught by someone they are comfortable with, the chance for hands-on learning and/or collaboration, and the chance to receive feedback concerning their learning.

Although two students suggested they would use an online tutorial to learn new skills, in general these students report that they do not use electronic resources such as help files or online tutorials. Their overwhelming preference is just to ask someone else, whether that is a family member, a friend, a classmate, or the person who happens to be sitting next to them.

\section{Self-views of Information Literacy}

All of the participants in this study reported feeling confident about their abilities as information seekers, and the scores they earned on the ILT substantiate these self-views. It is interesting, though, that they do not feel that they do or know anything special that their peers might not know. Rather, they discuss standing out in terms of their ability to put in the effort needed to find information, persevere with the search, and draw on their interest in learning. As one student put it, it is not the benefit of having the Internet, but rather, "The benefits of my curiosity."

Participants acknowledge that not all of their classmates perform at the level they do, but this is not generally regarded as a lack of skill or orientation. In fact, several of these students believe that young people are better information seekers than older adults are, due to the fact that they grew up with the Internet and believe they are more comfortable with computers and electronic sources than the older generation is.

These self-views are consistent with what would be expected from the point of view of competency theory. Previous research has shown that people with nonproficient skills tend to overestimate their ability, people who are highly skilled tend to underestimate their performance when comparing to peers, and that people with average abilities tend to make more accurate social comparisons. ${ }^{14}$

When asked how they would go about assessing the information-seeking abilities of their classmates, as with other questions, participants indicate that their focus would be on whether or not students could come up with the answer, not the process they used to get there, with a secondary interest in whether they evaluated the quality of the sources they chose to use. The concern here was that students should not just settle for anything and should demonstrate that they have put some effort into the process. Sources need to be appropriate to the question and credible. A few respondents also felt that the time it takes students to find the needed information would also be a useful metric for assessing their ability. Caring about the assignment and demonstrating patience, perseverance, and determination were seen as key personal characteristics needed for success. As above, no differentiation was made between imposed and self-generated information seeking.

\section{Conclusions}

The general view of information seeking presented here is best understood as the perceptions of students who are proficient information seekers. They present a view of information seeking that is very focused on product or outcome (can you find what 
is needed?) rather than the knowledge base and skills that lie behind the ability to achieve this result. These students emphasize, as keys to success, such characteristics as the ability to learn, the ability to be interested, and a willingness to put in the effort needed. Computer literacy, library skills, searching skills, and other "background" abilities such as assessing the quality of sources, thinking critically about information, and having an awareness of the legal and ethical issues related to information use are largely absent whether they are being overlooked or assumed.

Participants are aware of the need to assess the quality of resources, but they see this need as existing on a kind of sliding scale that is related to the importance of the question. Resource quality is an issue for school assignments and for personal issues of great importance, but otherwise it is likely to be ignored. Likewise, the use of multiple resources is related to imposed questions, such as school assignments, where they are commonly required. Otherwise, unless an interest is an ongoing one, such as for a hobby, information seeking stops when the answer is achieved. Interestingly, when participants were asked how they would evaluate the information seeking of their peers, respondents did hold up quality of resources as one rubric they would use. This may reflect their understanding that, in an academic setting, source quality is important; so they included it in an assessment scenario that took place within the context of the classroom.

This lack of emphasis on the knowledge base and specific skills needed to be a successful information seeker is also evidenced in the assumption that these are skills everyone has, that growing up with computers provides these skills, and that what you need to know can be self-taught. It also results in a lack of awareness that there is more to know about information seeking or that their abilities could be improved. While this group of participants did demonstrate proficiency, only one out of twenty students interviewed scored at the advanced level on the ILT, while 65 percent of the study group scored below 80 percent on the ILT. The majority of participants in this study represent the top 10 percent of their incoming class, yet their information literacy skill, as indicated by their scores on the ILT, are unexceptional. Two out of three students representing the bottom 10 percent of the entering class scored in the proficient range.

In terms of competency theory, these participants demonstrate views of their own ability that are realistic in terms of their demonstrated skills on the ILT. This investigation fails to bring in the point of view held by students who do not have proficient information literacy skills, so no comment can be made on how such students think about or experience information, nor can any comment be made on the miscalibrations between skill and selfestimates of skill that competency theory would expect from nonproficient students.

Several characteristics of imposed and self-generated information seeking are described by participants that provide a rich picture of how query type affects the experience of information seeking for these students. The constrained nature of school assignments as contrasted to the freedoms inherent in self-generated information seeking can both reinforce and dilute the tenets of information literacy as defined by librarians. For example, concern for source quality is understood as a prerequisite for school assignments, but otherwise it is considered only if there is a perception that having the wrong information will have a dire consequence. In most situations, poor information appears to pose little risk and so source quality may not be assessed.

Participants saw the importance of background knowledge and personal interest, particularly for imposed information seeking, as critical to their success. Students voiced a preference for assignments that gave them some room for personal choice, but they also noted that even this approach on the part of instructors may not be sufficient for them to do well. An inability to develop an interest 
in the subject or the assignment is seen as a major barrier to high performance, as it works against their ability to be self-motivated and engage with the assignment.

The use of people in information seeking was also demonstrated to play a central role in the acquisition of informationseeking skills as well as knowledge. These students report relying on others when they need information, as well as serving as sources for the information-seeking needs of others. Information help sought from people ranged from using people as informants because they are perceived as having the needed information, to using people as agents to find the needed information, to using people as tutors who will teach the information-seeking skills needed in the moment. While knowledge base is highly respected by these students, the perceived availability of the informant, agent, or tutor is often the factor that gets the most weight in choosing who to ask. Overall, participants prefer consulting human sources that they already have an established relationship with or people who are convenient to ask over tracking down a librarian or instructor.

\section{Implications for Practice}

In terms of implications for the design of learning interventions, the experience of these students provides much food for thought. The term "information literacy" did not resonate with these students, and they report having little formal information literacy training. If librarians and instructors want students to know this term, they will need to introduce it and explain what it means and find ways to connect this to both school work and personal information seeking. The strong emphasis on the need to be interested in their topic in imposed situations should be considered in developing information literacy interventions, as it is likely that students will not see this as an area of special skills and may not perceive the librarian as the most convenient source for developing or enhancing knowledge and skills when they are perceived as needed.
In designing interventions, student preferences for in-person learning over electronic sources, such as help files and self-paced tutorials, is worth considering. These students have a distinct preference for learning on their own and with peers. While a one-on-one learning situation is seen as optimal, classroom situations that allow for collaboration including handson activities and that respond to a specific and current need were also described as desirable.

The need to develop an interest, especially when working in an area that is not of interest, was voiced as a major issue with school assignments. The question of what can be done to help students transfer the motivation they feel in self-generated information seeking to imposed tasks is a skill that is not routinely addressed, but it could be a huge help to many in their information seeking. The students interviewed here have proficient information literacy skills, and this must be remembered when considering the points above. While it is possible that their experiences and conceptions of information are shared by other students, competency theory suggests that students who do not have proficient information literacy skills may have special instructional needs. ${ }^{15}$ The question of how librarians and instructors can identify and reach the nonproficient continues to be an open one. However, to help establish the need for attention to information-seeking skills, librarians and instructors may want to consider including information about the characteristics of the competent and incompetent in their presentations.

\section{Implications for Research}

The application of competency theory to information literacy represents a new approach to understanding how to improve student information literacy skills. More investigation is needed to determine to what extent competency theory applies to this skill domain and what kinds of help it can bring to students' understanding that information literacy encompasses a knowledge base and skill set that are formally defined 
and worth attaining. Little is known about how students themselves conceptualize and experience information and related information behaviors. This study has provided preliminary data on the perceptions of information held by mainly highachieving students who have proficient information literacy skills. Information is needed from other subgroups of students, particularly those who are not competent information seekers, as well as those who are expert to allow for the development of a model of student views of information literacy. The ultimate goal of this research is to be able to help students attain information literacy by providing interventions that will lead to an increase in the number of students nationwide who will enter the workforce with information literacy skills that serve them well throughout their lives.

\section{Notes}

1. Andrea L. Foster, "Students Fall Short on 'Information Literacy,' Education Testing Service's Study Finds," The Chronicle of Higher Education 53, no. 10 (Oct. 27, 2006): A36.

2. J. Coupe, "Undergraduate Library Skills: Two Surveys at Johns Hopkins University," Research Strategies 11 (1993): 189-201; A. Greer, L. Weston, and M. Alm, "Assessment of Learning Outcomes: A Measure of Progress in Library Literacy," College \& Research Libraries 52 (1991): 549-57; Patricia Davitt Maughan, "Assessing Information Literacy Among Undergraduates: A Discussion of the Literature and the University Of California-Berkeley Assessment Experience," College \& Research Libraries 62, no. 1 (2001): 71-85.

3. Melissa Gross and Don Latham, "Attaining Information Literacy: An Investigation of the Relationship Between Skill Level, Self Estimates of Skill, and Library Anxiety," Library \& Information Science Research 29 (2007): 332-53; Lucy Holman, "A Comparison of Computer-Assisted Instruction and Classroom Bibliographic Instruction," Reference \& User Services Quarterly 40, no. 1 (2000): 53-60; Elizabeth Blakesley Lindsay, Lara Cummings, Corey M. Johnson, and B. Jane Scales, "If You Build It, Will They Learn? Assessing Online Information Literacy Tutorials," College $\mathcal{E}$ Research Libraries 67, no. 5 (2006): 429-45, Maughan, "Assessing Information Literacy Among Undergraduates," 71-85.

4. Justin Kruger and David Dunning, "Unskilled and Unaware of It: How Difficulties in Recognizing One's Own Incompetence Lead to Inflated Self-Assessments," Journal of Personality and Social Psychology 77, no. 6 (1999): 1121-34; Joyce Ehrlinger, Kerrie Johnson, Matthew Banner, David Dunning, and Justin Kruger, "Why the Unskilled Are Unaware: Further Explorations of (Absent) Self-Insight among the Incompetent," Organizational Behavior and Human Decision Processes 105 (2008): 98-121.

5. Kruger and Dunning, "Unskilled and Unaware of It"; Ehrlinger et al., "Why the Unskilled Are Unaware," 99.

6. Melissa Gross, "The Impact of Low-Level Skills on Information Seeking Behavior: Implications of Competency Theory for Research and Practice," Reference and User Services Quarterly 45, no. 2 (2005): 54-62.

7. Gross and Latham, "Attaining Information Literacy."

8. Association of College and Research libraries (ACRL), Information Literacy Competency Standards for Higher Education (2006). Available online at www.ala.org/ala/acrl/acrlstandards/ informationliteracycompetency.htm. [Accessed 7 July 2006].

9. Christine Bruce, The Seven Faces of Information Literacy (Adelaide, Australia: Auslib Press Pty Ltd, 1997).

10. Ibid.

11. Gross and Latham, "Attaining Information Literacy."

12. Anslem C. Strauss and Juliet Corbin, Basics of Qualitative Research, 2nd ed. (Thousand Oaks, Calif.: Sage, 1998).

13. Lynn Cameron, Steven L. Wise, and Susan Lottridge, "The Development and Validation of the Information Literacy Test," College \& Research Libraries 68, no.3 (2007): 229-36.

14. Gross and Latham, "Attaining Information Literacy."

15. Gross, "The Impact of Low-Level Skills on Information Seeking Behavior." 


\section{Appendix A: Interview Guide}

\section{How old are you?}

\section{What is your major?}

3. We're interested in how people look for information. So, as a kind of warm-up to talking, see if you can remember working on a research paper assignment for school. This could be an assignment from spring semester or any other research assignment that stands out in your mind. By research assignment, we mean a school assignment where you had to find more information on your own. Think of an assignment where you had to go beyond reading assigned for class, such as in the class textbook, and find some other resources. Can you think of an example? Describe how you approached this information-seeking task.

4. Okay, let's try the same exercise again; but, instead of thinking about school assignments, see if you can think of a time just in your personal life when you needed information. This might be in relation to a hobby, or special interest you have, or something you wanted to accomplish that was important to your own life, such as finding a college, buying a car or a computer, or planning a vacation. Any kind of information that you needed that you sought out on your own. How did you go about finding and selecting the information you were looking for?

5. Okay, so we kind of did that to sort of begin thinking about the process of looking for information. And we're interested in both academic and everyday information seeking. In terms of your process in the two examples you gave as well as any other related experiences, to what extent are these types of information seeking the same or different?

Prompts

a. Do they require different skill sets?

b. Are there differences in how you think about your information-seeking task?

c. Are there other situations that require a different kind of information literacy?

6. How would you say that you learned what you know about looking for information? For example, some people went to schools where there were librarians, and they had class visits where they learned about how information is organized and the tools to access it. Some people have instructors that take time in class to really talk to them about how to look for information. Some people teach themselves, or learn from friends, or from their parents, or in more than one way. If you think back, how many ways have you learned what you know about looking for information?

Prompts

a. When have you asked friends, classmates, or others for help? How often does this happen?

b. When have others asked you for help? How often does this happen?

c. How much of what you know would you say you learned on your own?

7. How important do you think it is to be able to be good at finding information? Prompts

a. Is this only an issue at school?

b. Does the need for information play much of a part in your everyday life?

c. Is this ability something that will affect your future? 
8. How would you describe your own information literacy skills?

a. How important are technology skills versus critical thinking skills?

b. How important is the situation to your sense of your skill level? Do you feel more proficient in some situations than others (school, job, everyday life)?

c. How do you think your ability to find information compares to the ability of your classmates or friends?

9. What skills and knowledge do you think a person needs to have to be called information literate?

Prompts

a. Are these dependent on the situation?

b. How would you prioritize these?

10. Are there any information-seeking skills you don't have that you would like to acquire or skills you have that you would like to improve?

11. If you wanted to learn some aspect of information seeking: attain some new knowledge, new skill, or even strengthen an existing skill, what would be the most effective way for you to do that?

Prompts

a. Who would you want to teach you (librarian, teacher, friend, other)?

b. Online? In a classroom? One-on-one?

12. Here's another thought exercise. If I were to ask you to help me out by going to your class, the class you were talking about earlier, and if I told you that I wanted you to evaluate your classmates in that class, and determine for me what the level of information skills and knowledge are among your classmates, what kinds of things do you think you'd want to know about them, or measure, to be able to tell me if they are competent information seekers or not?

Prompts

a. What kind of knowledge should they have?

b. What skills do they need?

c. Would this evaluation only pertain to this class?

13. Okay. Let's imagine that we're done here, and you're leaving, you're walking over to the Assessment Center to take your Information Literacy Test, and you run into a friend, and your friend says, "You know, I was just in my class and my teacher was going on and on and on about information literacy. I don't have a clue what that was." How you would answer that question for your friend?

14. Is there anything else you would like to tell us about searching for information? 